\title{
COVID-19 Related Psychological Distress, Fear and Coping: Identification of High-Risk Groups in Bangladesh
}

\section{OPEN ACCESS}

Edited by:

Elnara Shafiyeva,

Baku State University, Azerbaijan

Reviewed by:

Seong Leang Cheah, University of Technology

Sydney, Australia

Ling Wang,

King's College London,

United Kingdom

*Correspondence:

Muhammad Aziz Rahman ma.rahman@federation.edu.au; aziz.rahman@y7mail.com Tamanna Bahar

tamanna.bahar@gmail.com

Specialty section:

This article was submitted to

Public Mental Health,

a section of the journal

Frontiers in Psychiatry

Received: 01 June 2021

Accepted: 20 July 2021

Published: 13 August 2021

Citation:

Rahman MA, Rahman S, Wazib A, Arafat SMY, Chowdhury ZZ, Uddin BMM, Rahman MM, Bahar

Moni AS, Alif SM, Sultana F,

Salehin M, Islam SMS, Cross W and Bahar T (2021) COVID-19 Related

Psychological Distress, Fear and Coping: Identification of High-Risk

Groups in Bangladesh.

Front. Psychiatry 12:718654. doi: 10.3389/fpsyt.2021.718654

\begin{abstract}
Muhammad Aziz Rahman 1,2,3,4*, Shaila Rahman ${ }^{5}$, Amit Wazib ${ }^{5}$, S. M. Yasir Arafat ${ }^{5}$, Zulfia Zinat Chowdhury 6 , Bhuiyan Mohammad Mahtab Uddin ${ }^{5}$, Mufti Munsurar Rahman ${ }^{5}$, Ahmed Suparno Bahar Moni ${ }^{7}$, Sheikh M. Alif ${ }^{8}$, Farhana Sultana ${ }^{9,10}$, Masudus Salehin ${ }^{1}$, Sheikh Mohammed Shariful Islam ${ }^{11}$, Wendy Cross $^{1}$ and Tamanna Bahar ${ }^{6 *}$

${ }^{1}$ School of Health, Federation University Australia, Berwick, VIC, Australia, ${ }^{2}$ Australian Institute for Primary Care and Ageing, La Trobe University, Melbourne, VIC, Australia, ${ }^{3}$ Department of Noncommunicable Diseases, Bangladesh University of Health Sciences, Dhaka, Bangladesh, ${ }^{4}$ Faculty of Public Health, Universitas Airlangga, Surabaya, Indonesia, ${ }^{5}$ Enam Medical College and Hospital, Savar, Bangladesh, ${ }^{6}$ National Institute of Cancer Research and Hospital, Dhaka, Bangladesh, ${ }^{7}$ Advanced Medical and Dental Institute, Universiti Sains Malaysia, Penang, Malaysia, ${ }^{8}$ School of Public Health and Preventive Medicine, Monash University, Melbourne, VIC, Australia, ${ }^{9}$ Telstra Health, Melbourne, VIC, Australia, ${ }^{10}$ Melbourne School of Population and Global Health, University of Melbourne, Carlton, VIC, Australia, ${ }^{11}$ Institute for Physical Activity and Nutrition, Deakin University, Burwood, VIC, Australia
\end{abstract}

Background: The COVID-19 pandemic has imposed psychological distress and fear across the globe; however, factors associated with those issues or the ways people cope may vary by country or context. This study aimed to investigate the factors associated with psychological distress, fear, and coping strategies for people living in Bangladesh during the COVID-19 pandemic.

Methods: A cross-sectional study conducted in August-September 2020 using online platforms in Bangladesh. People residing in Bangladesh, aged $\geq 18$ years, who were proficient in English and able to respond to online questionnaire. The Kessler Psychological Distress Scale was used to assess the psychological stress. Level of fear was assessed using the Fear of COVID-19 Scale, and strategies to cope were assessed using the Brief Resilient Coping Scale.

Results: Of the 962 participants, half of them were aged between 30 and 59 years. Being born in Bangladesh, having graduate education, perceived distress due to employment change, effect of COVID-19 on financial situation, having multiple comorbidities, and visiting a healthcare provider in the last 4 weeks were associated with higher levels of both psychological distress and fear of COVID-19. Furthermore, higher psychological distress was associated with being a female (AOR 1.81, 95\% Cl 1.33-2.47, $p<0.001$ ), being a frontline worker (AOR 1.50, 95\% Cl 1.04-2.15, $p<0.05$ ), having pre-existing psychiatric problems (AOR 4.03, 95\% Cl 1.19-13.7, $p<0.05$ ), being a smoker (AOR 2.02, 95\% Cl 1.32-3.09, $p<0.01$ ), providing care to a known/suspected COVID-19 patient (AOR 1.96, 95\% Cl 1.40-2.72, $p<0.001$ ), having a recent overseas travel history and being in self-quarantine (AOR 4.59, 95\% Cl 1.23-17.2, $p<0.05$ ), self-isolation without COVID-19 (AOR 2.63, 95\% Cl 1.68-4.13, $p<0.001$ ) or being 
COVID-19 positive (AOR 2.53, 95\% Cl 1.19-5.34, $p<0.05$ ), and having high levels of fear of COVID-19 (AOR 3.27, 95\% Cl 2.29-4.66, $p<0.001$ ). A higher level of fear was associated with moderate to high levels of psychological distress (AOR 3.29, 95\% Cl 2.31-4.69, $p<0.001$ ). People with pre-existing mental health problems were less likely to be resilient (AOR $0.25,95 \% \mathrm{Cl} 0.11-0.54, p<0.01$ ), whereas those with having an income were more likely to be resilient (AOR 1.46, 95\% Cl 1.02-2.11, $p<0.05$ ).

Conclusion: Effective interventions to support the vulnerable groups including improved access to mental health services are of utmost importance during the pandemic.

Keywords: COVID-19, mental health, psychological distress, coping, resilience, Bangladesh

\section{INTRODUCTION}

The COVID-19 pandemic has affected more than 218 countries and territories across the world. Globally more than 140 million cases of COVID-19 and nearly 3 million deaths due to COVID 19 have been reported to date (1). The United States of America has reported the highest number of cases and deaths due to COVID-19 followed by India, Brazil, France, Russian Federation, the United Kingdom, Turkey, Italy and Spain. In Bangladesh, the first three cases of COVID-19 were detected on 8th March 2020. To date, around 715,252 confirmed COVID-19 cases and 10,283 deaths have been reported in Bangladesh (2). The Government of Peoples Republic of Bangladesh has developed a Multisectoral Action Plan in response to the COVID-19 pandemic preparedness. This includes lockdown in major cities, practizing of social distancing, closing of schools and universities, working from home arrangements where possible, widespread awareness campaigns for handwashing practices, complementary use of masks in public places including when using public transport, imposing regulation on international travel from hotspots, establishing quarantine centers, mandatory quarantine for COVID-19 suspected cases, and isolation of confirmed cases. Moreover, there are guidelines for COVID-19 clinical management, designation of public and private hospitals for treating positive cases, establishing isolation units in different hospitals, nationwide testing facilities, dissemination through health bulletins and tracking of COVID-19 infections and deaths through published data $(3,4)$.

Nationwide vaccination program has started in Bangladesh from February 7, 2021 (5). Despite all the Government efforts, Bangladesh had been experiencing the second wave of infection, started from March 1, 2021 (2). The strict restrictions on daily activities, social life and travel, the livelihood of the general population had been severely affected. Daily wage-earners have been affected most because of the restrictions on businesses, movement and public activities. Despite having a low case fatality rate $(1.43 \%)$ compared to other countries, people are generally anxious and distressed due to the increasing number of new cases in the community and fear of death of those near and dear $(4,5)$.

During the early days of the pandemic, many frontline healthcare workers including emergency service providers such as police, armed forces personnel, bankers, and government officials were infected with COVID-19 (6). The scarcity of personal protective equipment, lack of an evidence-based treatment protocol, scarcity of resources made healthcare workers worried. Furthermore, healthcare workers were humiliated for providing care to COVID-19 and were asked to isolate and stay away from the community and families to curb the further spread of infection. This imposed enormous psychological distress and fear amongst the health workforce (7).

Several previous studies have found evidence of anxiety, depression, fear, sleep deprivation, and self-harm among community members during the pandemic (8). Studies also have shown that the COVID-19 pandemic affected people in different countries in different ways with some groups being more vulnerable than others. A recent review found that women, younger individuals, those living in rural areas, those with lower socioeconomic status, those are at high-risk of COVID-19 infection due to their work or high risk of having severe infection due to presence of comorbidities are associated with higher levels of anxiety and depression (9). In an Australian study, pre-existing mental health conditions, increased smoking and alcohol consumption during the locked down period, being female were associated with higher levels of psychological distress (10). In an Italian study, female gender, detachment with the friends and families were associated with higher levels of anxiety and stress (11). A recent study in China reported moderate to severe anxiety symptoms, distress, and depressive symptoms among community people (12). Few studies have been conducted in Bangladesh to assess the extent of mental health status during COVID-19 pandemic in different populations using different tools and methodologies. A study by Zubayer et al. showed moderate to extremely severe levels of depression, anxiety, and stress in the general population (4). Another study by Islam et al. showed a high prevalence of panic (79.6\%) and generalized anxiety (37.3\%) in the general Bangladeshi population. Generalized anxiety was observed more in females, those older than 30 years, who were married, had higher education and were non-governmental employees (13). Another study was conducted among healthcare workers working in a central public hospital that reported depression and anxiety and insomnia amongst 50 and $55 \%$ of the doctors, respectively (7).

Currently, there are very limited studies in Bangladesh assessing the factors associated with COVID-19 related distress, fear and coping strategies. In this study we aimed to assess the 
extent of psychological distress and the level of fear of COVID-19 among the Bangladeshi population and their coping strategies along with associated factors using previously validated tools. The high-risk groups of individuals identified through this study, could be targeted as the vulnerable groups who would require additional support for psychological well-being during the crisis period such as this pandemic.

\section{METHODS}

\section{Study Design and Settings}

A cross-sectional study was conducted between August and September 2020, where participants from the community as well as clinical settings were approached via different online platforms.

\section{Study Population}

People residing in Bangladesh (irrespective of nationality) during the study period, aged $\geq 18$ years and capable of responding to an online questionnaire in English, were eligible for this study. Study participants consisted of general community members including COVID-19 patients, students, and healthcare professionals. If any study participant took $<1 \mathrm{~min}$ to complete the questionnaire, he/she was excluded from the analyses due to unreliability of the responses.

\section{Sampling Technique and Sample Size}

The Snowball sampling technique was used for collecting data. Once a participant filled up the online questionnaire, he/she was requested to forward the survey link to his/her personal /professional networks. The sampling technique was similar to our previous study, described elsewhere (10). The sample size was calculated using OpenEpi. Considering 164.71 million population of Bangladesh (14) assuming 50\% prevalence of stress among the Bangladeshi (since no existing national data available on the prevalence of stress among Bangladeshis), at 95\% confidence intervals and $80 \%$ power, the estimated minimum sample size was 385 .

\section{Data Collection Tools and Technique}

A structured survey questionnaire was developed using Google form. The survey was open as anyone having the survey link could participate in the study. All the contacts were made via online using emails, text messages and social media platforms such as Facebook, LinkedIn and Twitter. The survey was advertised via online platforms including emails, texts and social media. The emails and text messages were sent utilizing the professional and personal networks of the local study investigators, which included health professionals and students of the affiliated medical collages/hospitals. Besides personal social media platforms, the survey link was also shared to social media groups of general community people of Bangladesh. There were nine screens in total. The first screen of the online questionnaire contained the plain language statement and the consent form. The plain language statement mentioned about the aims of the study, types of data collected, anonymity of the responses collected, privacy and confidentiality
TABLE 1 | Characteristics of the study population.

\begin{tabular}{|c|c|}
\hline Characteristics & Total, $\boldsymbol{n}(\%)$ \\
\hline Total study participants & 962 \\
\hline Age (in years) & 962 \\
\hline Mean $( \pm S D)$ & $32.2(10.7)$ \\
\hline Range & 18 to 76 \\
\hline Age groups & 962 \\
\hline 18-29 years & $453(47.1)$ \\
\hline 30-59 years & $478(49.7)$ \\
\hline$\geq 60$ years & $31(3.2)$ \\
\hline Gender & 928 \\
\hline Male & 460 (49.6) \\
\hline Female & $468(50.4)$ \\
\hline Location in Bangladesh & 928 \\
\hline Dhaka & $678(73.1)$ \\
\hline Chottogram & $59(6.4)$ \\
\hline Sylhet & $18(1.9)$ \\
\hline Rajshahi & $58(6.3)$ \\
\hline Rangpur & $34(3.7)$ \\
\hline Khulna & $40(4.3)$ \\
\hline Barisal & $21(2.3)$ \\
\hline Myemensigh & $20(2.2)$ \\
\hline Residence location in Bangladesh & 928 \\
\hline Urban & $674(72.6)$ \\
\hline Rural & $254(27.4)$ \\
\hline Living status & 908 \\
\hline $\begin{array}{l}\text { Live without family members (on your own/shared } \\
\text { house/others) }\end{array}$ & $94(10.4)$ \\
\hline Live with family members (partner and/or children) & $814(89.6)$ \\
\hline Born in Bangladesh & 927 \\
\hline No & $17(1.8)$ \\
\hline Yes & $910(98.2)$ \\
\hline Completed level of education & 923 \\
\hline Primary & $25(2.7)$ \\
\hline Secondary & $257(27.8)$ \\
\hline Trade/Certificate/Diploma & $17(1.8)$ \\
\hline Degree (Bachelor) & $322(34.9)$ \\
\hline Masters and above & $302(32.7)$ \\
\hline Current employment condition & 909 \\
\hline Unemployed/Housewife (No source of income) & $334(36.7)$ \\
\hline $\begin{array}{l}\text { Jobs affected by COVID-19 (lost job/working hours } \\
\text { reduced/afraid of job loss) }\end{array}$ & $109(12.0)$ \\
\hline Have an income source (employed/Government benefits) & 466 (51.3) \\
\hline Perceived distress due to change of employment status & 889 \\
\hline A little to none & $510(57.4)$ \\
\hline Moderate to a great deal & $379(42.6)$ \\
\hline Self-identification as a frontline or essential service worker & 892 \\
\hline No & $464(52.0)$ \\
\hline Yes & $428(48.0)$ \\
\hline COVID-19 impacted financial situation & 928 \\
\hline No & 339 (36.5) \\
\hline Yes & 589 (63.5) \\
\hline Co-morbidities & 922 \\
\hline
\end{tabular}

(Continued) 
TABLE 1 | Continued

\begin{tabular}{|c|c|}
\hline Characteristics & Total, $n(\%)$ \\
\hline No & $599(65.0)$ \\
\hline Multiple co-morbidities & 95 (10.3) \\
\hline Hypertension & $69(7.5)$ \\
\hline Psychiatric/Mental health problem & $39(4.2)$ \\
\hline Cancer & $37(4.0)$ \\
\hline Chronic respiratory diseases & $28(3.0)$ \\
\hline High blood lipids & $20(2.2)$ \\
\hline Diabetes/High blood sugar & $18(2.0)$ \\
\hline Heart diseases & $7(0.8)$ \\
\hline Chronic orthopedic problems & $5(0.5)$ \\
\hline Stroke & $1(0.1)$ \\
\hline Smoking & 928 \\
\hline Never smoker & $751(80.9)$ \\
\hline Ever smoker (Daily/Non-daily/Ex) & $177(19.1)$ \\
\hline Increased smoking in the last 4 weeks & 117 \\
\hline No & $80(68.40)$ \\
\hline Yes & 37 (31.6) \\
\hline Current alcohol drinking (last 4 weeks) & 918 \\
\hline No & $888(96.7)$ \\
\hline Yes & $30(3.3)$ \\
\hline Increased alcohol drinking over the last 4 weeks & 26 \\
\hline No & $19(73.1)$ \\
\hline Yes & $7(26.9)$ \\
\hline $\begin{array}{l}\text { Provided care to a family member/patient with known/suspected } \\
\text { case of COVID-19 }\end{array}$ & 919 \\
\hline No & $441(48.0)$ \\
\hline Yes & $478(52.0)$ \\
\hline $\begin{array}{l}\text { Experience related to COVID-19 pandemic (multiple responses } \\
\text { possible) }\end{array}$ & 886 \\
\hline No known exposure to COVID-19 & $635(71.7)$ \\
\hline I had recent overseas travel history and was in self-quarantine & $27(3.0)$ \\
\hline I had been tested negative for COVID-19 but self-isolating & $164(18.5)$ \\
\hline I had been tested positive for COVID-19 & $60(6.8)$ \\
\hline $\begin{array}{l}\text { Self-identification as a patient (visited a healthcare provider in the } \\
\text { last } 4 \text { weeks) }\end{array}$ & 916 \\
\hline No & $658(71.8)$ \\
\hline Yes & $258(28.2)$ \\
\hline Healthcare service use in the last 4 weeks & 361 \\
\hline Telehealth consultation/Use of national helpline & $151(41.8)$ \\
\hline In-person visit to a healthcare provider & $200(55.4)$ \\
\hline Used both services & $10(2.8)$ \\
\hline $\begin{array}{l}\text { Healthcare service use to overcome COVID-19 related stress in } \\
\text { the last } 4 \text { weeks }\end{array}$ & 915 \\
\hline No & $846(92.5)$ \\
\hline Yes & $69(7.5)$ \\
\hline
\end{tabular}

of the collated data, data storage, details of investigators. On providing consent, participants could move to the next screen containing the screening questionnaire related to eligibility. If eligible, participants could proceed to filling out the full study questionnaire in the subsequent seven screens. No randomisation technique was applied for the questionnaire and adaptive questioning was used as applicable. The completeness of the questionnaire was indicated by the progress bar in the online questionnaire. There were also options of responding as "not applicable" or "no response". Study participants had the options to go back and review/edit their responses accordingly.

Same questionnaire was used from the previous study conducted in Australia and Malaysia by the same research group (10). Psychological distress was measured using the Kessler Psychological Distress Scale (K-10), $(15,16)$ fear was measured using the Fear of COVID-19 Scale (FCV-19S), (17) and coping strategies were measured using Brief Resilient Coping Scale (BRCS) (18). The K-10 tool is a widely used psychometric tool, validated in different languages including English and used for public health research $(15,16)$ [the FCV-19S tool was recently developed in response to the COVID-19 pandemic, which has also been validated and used in many studies $(17,19,20)$ validity and reliability have been tested for the BRCS tool in previous studies $(18,21,22)$. Notably, they were recorded using a five-point Likert scale. There were two screening questions to determine eligibility to participate in the study, which was followed by a total of 39 questions. The details of each of the items are published in our previous study (10). A pretest of the adapted version of the questionnaire was performed on a selective group of participants and the modification were completed before the data collection. Internal consistency of the questionnaire was satisfactory in the pilot study (data not shown). In addition, to minimize non-response bias, the following measures were adopted: the final questionnaire was pre-tested in both desktops/laptops/mobile phones/ipads so that the questionnaire appears correctly across all devices for the convenience of participants, a period of 2 months data collection period was ensured, survey reminders were sent to all potential participants across different networks at least three times within the data collection period. No incentive was provided to any study participant. In Bangladesh, essential service workers encompassed those individuals from essential workplaces including healthcare settings, pharmacies, food and groceries, schools and universities, public transports. Patients and/or the public were not involved in the design, conduct, reporting or dissemination plans of this research.

\section{Data Analyses}

The database was downloaded from the Google platform and STATA v.12 was used for data analyses. Only completed questionnaire $(n=962)$ were analyzed. Descriptive analyses were followed by inferential analyses. Continuous variables were presented as means and standard deviations, and categorical variables were presented as proportions. Scoring in the K10 scale was re-defined into low (score 10-15) and moderate to very high (score 16-50), fear of COVID score was defined as BRCS categorized into low (score 4-13) and medium to high (score 14-20) resilient coping. Binary logistic regression was used to assess the association, results were presented as odds ratio (OR) and $95 \%$ confidence interval (CI). Multivariate analyses were conducted by adjusting for socio-demographic variables such as age, gender, living status, country of birth, education, and 
TABLE 2 | Levels of psychological distress among the study participants.

\begin{tabular}{|c|c|c|c|c|c|c|}
\hline Anxiety and Depression Checklist (K10) (last 4 weeks) & Total & $\begin{array}{l}\text { None, } \\
n(\%)\end{array}$ & $\begin{array}{c}\text { A little, } \\
\text { n (\%) }\end{array}$ & $\begin{array}{l}\text { Sometime, } \\
n(\%)\end{array}$ & $\begin{array}{l}\text { Most of the } \\
\text { time, } n(\%)\end{array}$ & $\begin{array}{c}\text { All the time, } \\
n(\%)\end{array}$ \\
\hline 1. About how often did you feel tired out for no good reason? & 928 & $217(23.4)$ & 179 (19.3) & $377(40.6)$ & $137(14.8)$ & $18(1.9)$ \\
\hline 2. About how often did you feel nervous? & 928 & $232(25.0)$ & $259(27.9)$ & $332(35.8)$ & $91(9.8)$ & $14(1.5)$ \\
\hline 3. About how often did you feel so nervous that nothing could calm you down? & 928 & $492(53.0)$ & $217(23.4)$ & $174(18.8)$ & $42(4.5)$ & $3(0.3)$ \\
\hline 4. About how often did you feel hopeless? & 928 & 337 (36.3) & $232(25.0)$ & $226(24.4)$ & $110(11.9)$ & $23(2.5)$ \\
\hline 5. About how often did you feel restless or fidgety? & 928 & $379(40.8)$ & $238(25.6)$ & $220(23.7)$ & $80(8.6)$ & $11(1.2)$ \\
\hline 6. About how often did you feel so restless you could not sit still? & 928 & $562(60.6)$ & $203(21.9)$ & $124(13.4)$ & $34(3.7)$ & $5(0.5)$ \\
\hline 7. About how often did you feel so depressed? & 928 & $304(32.8)$ & $227(24.5)$ & $268(28.9)$ & $104(11.2)$ & $25(2.6)$ \\
\hline 8. About how often did you feel that everything was an effort? & 928 & $308(33.2)$ & $243(26.2)$ & $246(26.5)$ & $105(11.3)$ & $26(2.8)$ \\
\hline 9. About how often did you feel so sad that nothing could cheer you up? & 928 & $392(42.2)$ & $226(24.4)$ & $217(23.4)$ & $77(8.0)$ & $16(1.7)$ \\
\hline 10. About how often did you feel worthless? & 928 & $446(48.1)$ & $218(23.5)$ & $174(18.8)$ & $64(6.9)$ & $26(2.8)$ \\
\hline K10 score (total) & 928 & & & & & \\
\hline Mean $( \pm S D)$ & $21.0(8.2)$ & & & & & \\
\hline Range & 10 to 50 & & & & & \\
\hline Level of psychological distress (K10 categories) & 928 & & & & & \\
\hline Low (score 10-15) & $284(30.6)$ & & & & & \\
\hline Moderate (score 16-21) & $243(26.2)$ & & & & & \\
\hline High (score 22-29) & 246 (26.5) & & & & & \\
\hline Very high (score 30-50) & $155(16.7)$ & & & & & \\
\hline
\end{tabular}

employment status. Then we reported adjusted OR (AOR) and 95\% CI. Details of the analyses were discussed in the earlier study (10).

\section{Ethics}

The study obtained approval from the Ethical Review Committee at Enam Medical College (Ref: EMC/ERC/2020/08-2). The survey was completely voluntary in nature and it was clarified in the plain language statement to explain it well, so that participants got the opportunity to have informed decision to participate in the study. No identifying information including any personal sensitive information were collected. Responses were anonymous and non-identifiable data were handled only by the investigators listed in the study.

\section{RESULTS}

A total of 1,016 people responded to the online survey, while 962 participants were included in this study (response rate was 95\%). All respondents did not report the demographic information and responded to all questions, therefore, the total number of responses for each variable did not sum up to the total number of 962. Almost all of them were born in Bangladesh (98\%), three-quarters of the study population were from the Dhaka division $(n=678,73.1 \%)$ and lived in urban areas $(n$ $=674,72.6 \%)$ with the majority living with family members (814, 90\%). Half of the participants $(n=478,49.7 \%)$ belonged to the age group of $30-59$ years and half were female (468, $50.4 \%)$. Almost two-thirds of the respondents had completed graduation $(n=624,68 \%)$ and half of them had an income source during the pandemic (51\%). While more than half of the participants reported that COVID-19 impacted their financial situation (64\%), a little less than half reported moderate to great deal of perceived distress due to change in employment status $(43 \%)$. Only a small proportion $(7.5 \%)$ sought healthcare services to overcome COVID-related stress in the last 4 weeks. Frontline or essential service workers constituted half of the study population $(n=428,48 \%)$ and over a quarter of the participants $(n=258,28.2 \%)$ visited a healthcare provider in the last 4 weeks. Almost half of the respondents provided care to a family member/patient with known or suspected case of COVID19 (52\%). One in 10 participants $(n=95,10.3 \%)$ reported having multiple co-morbidities and one in five reported having ever smoked (19\%). Details of the characteristics of the study population are presented in Table $\mathbf{1 .}$

More than two-thirds of the study participants $(n=530$, $69.4 \%$ ) experienced moderate to very high levels of psychological distress, and the mean ( \pm SD) K-10 score was 21 (8.2) (Table 2). More than one-third of the participants ( $n=357,38.5 \%)$ reported high levels of fear of COVID-19, and the mean $( \pm S D)$ FCV-19S score was 19.1 (7.3) (Table 3). More than half of the participants ( $n=530,57.1 \%$ ) had medium to high resilient coping and the mean ( \pm SD) BRCS score was 13.9 (3.2) (Table 4).

\section{Psychological Distress}

Table 5 shows unadjusted and adjusted analyses for identifying factors associated with moderate to very high psychological distress. Following adjustment of potential confounders, higher levels of psychological distress were found to be associated with being a female, born in Bangladesh, having a graduate or above level of education. A range of other factors were also associated with higher distress, such as having moderate to a great deal of perceived distress, including change in employment, being a frontline/essential service worker, impacted financial situation 
TABLE 3 | Levels of fear of COVID-19 among the study participants.

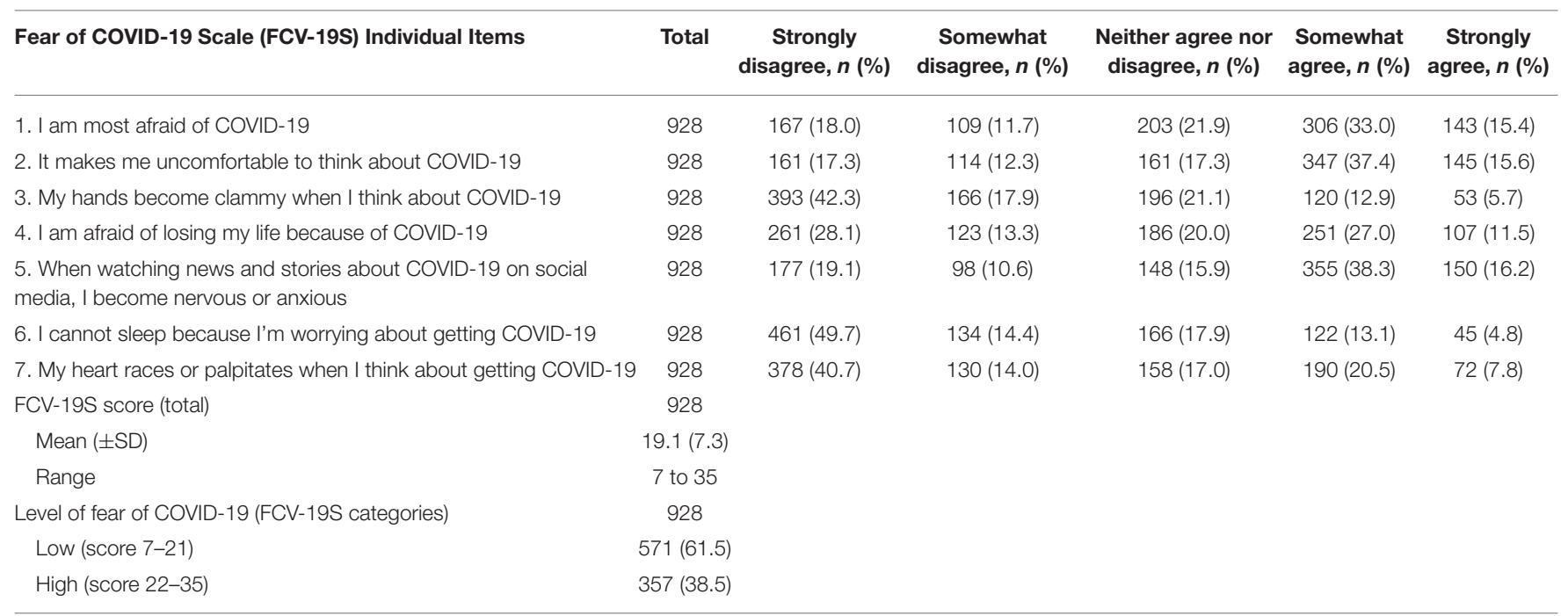

TABLE 4 | Coping during COVID-19 pandemic among the study participants.

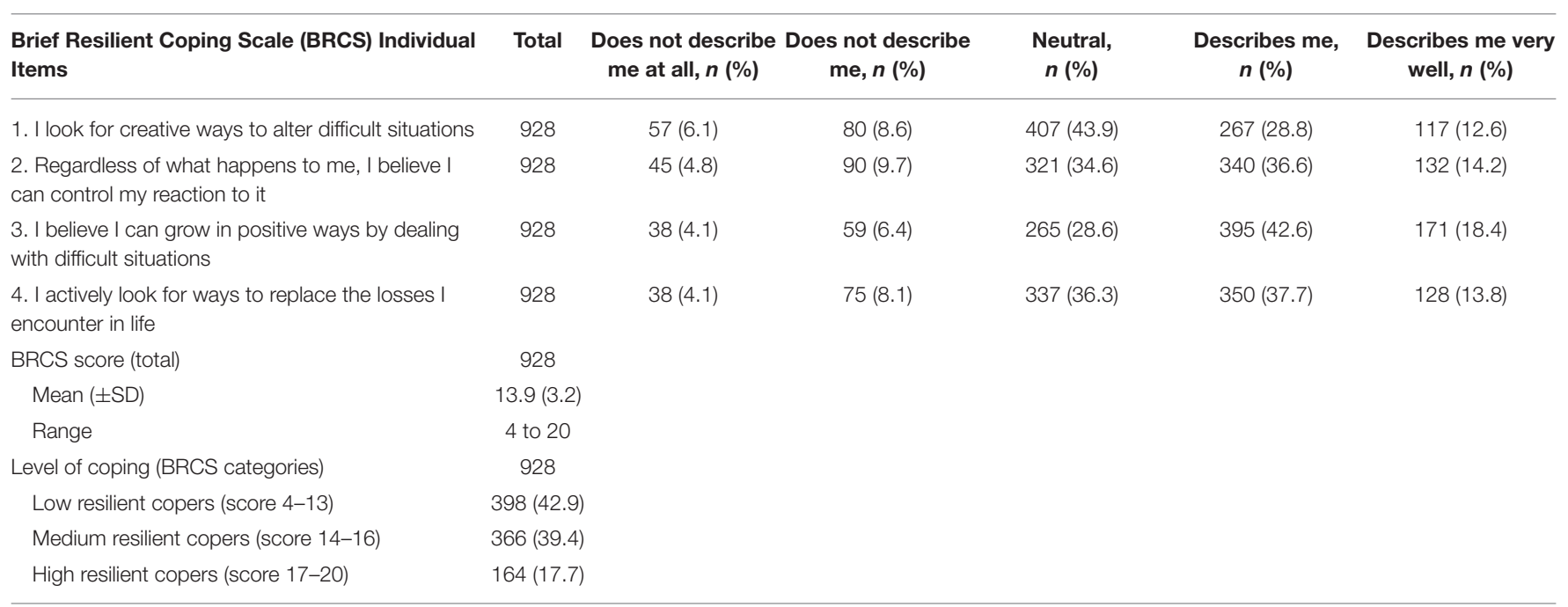

due to COVID-19, having psychiatric/mental health problems, having multiple co-morbidities, being a smoker (at any time), providing care to a known/suspected case of COVID-19, having a recent overseas travel history and being in self-quarantine, having negative test results for COVID-19 but being in self-isolation, having positive test results for COVID-19, being a patient, and having higher levels of fear of COVID-19. In contrast, living in a rural area and having an income source during the pandemic were associated with lower levels of psychological distress following adjustment of potential confounders.

\section{Fear of COVID-19}

Higher levels of fear of COVID-19 were associated with several factors following adjustment of potential confounders, such as living with family members, being born in Bangladesh, having Bachelors and Masters level of education or above, having moderate to a great deal of perceived distress due to changes in employment, impacted financial situation due to COVID-19, having multiple co-morbidities, being a patient, and having moderate to very high level of psychological distress (Table 6).

\section{Coping Strategies}

Multivariate analyses showed that study participants who had an income source had medium to high resilient coping, whereas those with pre-existing psychiatric/mental health problems had low resilient coping (Table 7).

\section{DISCUSSION}

This is one of the first studies carried out among Bangladeshi residents using validated tools to assess the extent and factors associated with psychological distress, level of fear, and coping strategies during the COVID-19 pandemic. Several factors were identified that were associated with a higher level of psychological 
TABLE 5 | Factors associated with moderate to very high psychological distress among the study participants (based on K10 score).

\begin{tabular}{|c|c|c|c|c|c|c|c|c|}
\hline Characteristics & $\begin{array}{l}\text { Moderate to very high } \\
\text { (score 16-50), } n(\%)\end{array}$ & $\begin{array}{l}\text { Low (score 10-15), } \\
n(\%)\end{array}$ & \multicolumn{3}{|c|}{ Unadjusted analyses } & \multicolumn{3}{|c|}{ Adjusted analyses } \\
\hline Age groups & 644 & 284 & & & & & & \\
\hline $18-29$ years & $317(49.2)$ & $119(41.9)$ & & 1 & & & 1 & \\
\hline $30-59$ years & $306(47.5)$ & $156(54.9)$ & 0.036 & 0.74 & $0.55-0.98$ & 0.295 & 0.85 & $0.62-1.16$ \\
\hline Gender & 644 & 284 & & & & & & \\
\hline Male & $284(44.1)$ & $176(62.0)$ & & 1 & & & 1 & \\
\hline Female & 360 (55.9) & $108(38.0)$ & 0.000 & 2.07 & $1.55-2.75$ & 0.000 & 1.81 & $1.33-2.47$ \\
\hline Living status & 634 & 274 & & & & & & \\
\hline $\begin{array}{l}\text { Live without family members (on your own/shared } \\
\text { house/others) }\end{array}$ & $60(9.5)$ & $34(12.4)$ & & 1 & & & 1 & \\
\hline Rural & $138(21.4)$ & $116(40.8)$ & 0.000 & 0.40 & $0.29-0.53$ & 0.000 & 0.38 & $0.27-0.54$ \\
\hline Born in Bangladesh & 643 & 284 & & & & & & \\
\hline No & $8(1.2)$ & $9(3.2)$ & & 1 & & & 1 & \\
\hline Yes & $635(98.8)$ & $275(96.8)$ & 0.044 & 2.60 & $0.99-6.80$ & 0.012 & 3.74 & $1.34-10.5$ \\
\hline Completed level of education & 639 & 284 & & & & & & \\
\hline Primary & $11(1.7)$ & $14(4.9)$ & & 1 & & & 1 & \\
\hline Secondary & $166(26.0)$ & $91(32.0)$ & 0.047 & 2.32 & $1.01-5.32$ & 0.158 & 1.92 & $0.78-4.72$ \\
\hline Trade/Certificate/Diploma & $9(1.4)$ & $8(2.8)$ & 0.570 & 1.43 & $0.42-4.93$ & 0.666 & 1.34 & $0.35-5.07$ \\
\hline Degree (Bachelor) & $239(37.4)$ & $83(29.2)$ & 0.002 & 3.66 & $1.60-8.39$ & 0.008 & 3.52 & $1.38-8.96$ \\
\hline Masters and above & $214(33.5)$ & $88(31.0)$ & 0.007 & 3.10 & $1.35-7.08$ & 0.045 & 2.62 & $1.02-6.70$ \\
\hline Moderate to a great deal & $295(48.0)$ & $84(30.7)$ & 0.000 & 2.09 & $1.54-2.82$ & 0.000 & 2.32 & $1.63-3.29$ \\
\hline $\begin{array}{l}\text { Self-identification as a frontline or essential service } \\
\text { worker }\end{array}$ & 621 & 271 & & & & & & \\
\hline No & $304(49.0)$ & $160(59.0)$ & & 1 & & & 1 & \\
\hline Yes & $317(51.0)$ & $111(41.0)$ & 0.006 & 1.50 & $1.13-2.01$ & 0.030 & 1.50 & $1.04-2.15$ \\
\hline COVID-19 impacted financial situation & 644 & 284 & & & & & & \\
\hline No & $215(33.4)$ & $124(43.7)$ & & 1 & & & 1 & \\
\hline Yes & $429(66.6)$ & $160(56.3)$ & 0.003 & 1.55 & $1.16-2.06$ & 0.000 & 2.05 & $1.49-2.84$ \\
\hline Co-morbidities & 638 & 284 & & & & & & \\
\hline No & 395 (61.9) & $204(71.8)$ & & 1 & & & 1 & \\
\hline Psychiatric/Mental health problem & $36(5.6)$ & $3(1.1)$ & 0.003 & 6.20 & $1.89-20.4$ & 0.025 & 4.03 & $1.19-13.7$ \\
\hline Other co-morbidities* & $132(20.7)$ & $57(20.1)$ & 0.321 & 1.20 & $0.84-1.70$ & 0.062 & 1.46 & $0.98-2.16$ \\
\hline Multiple co-morbidities & $75(11.8)$ & $20(7.0)$ & 0.013 & 1.94 & $1.15-3.26$ & 0.007 & 2.17 & $1.24-3.80$ \\
\hline Smoking & 644 & 284 & & & & & & \\
\hline Never smoker & $513(79.7)$ & $238(83.8)$ & & 1 & & & 1 & \\
\hline Ever smoker (Daily/Non-daily/Ex) & $131(20.3)$ & $46(16.2)$ & 0.139 & 1.32 & $0.91-1.91$ & 0.001 & 2.02 & $1.32-3.09$ \\
\hline Increased smoking in the last 4 weeks & 94 & 23 & & & & & & \\
\hline No & $61(64.9)$ & 19 (82.6) & & 1 & & & 1 & \\
\hline
\end{tabular}


TABLE 5 | Continued

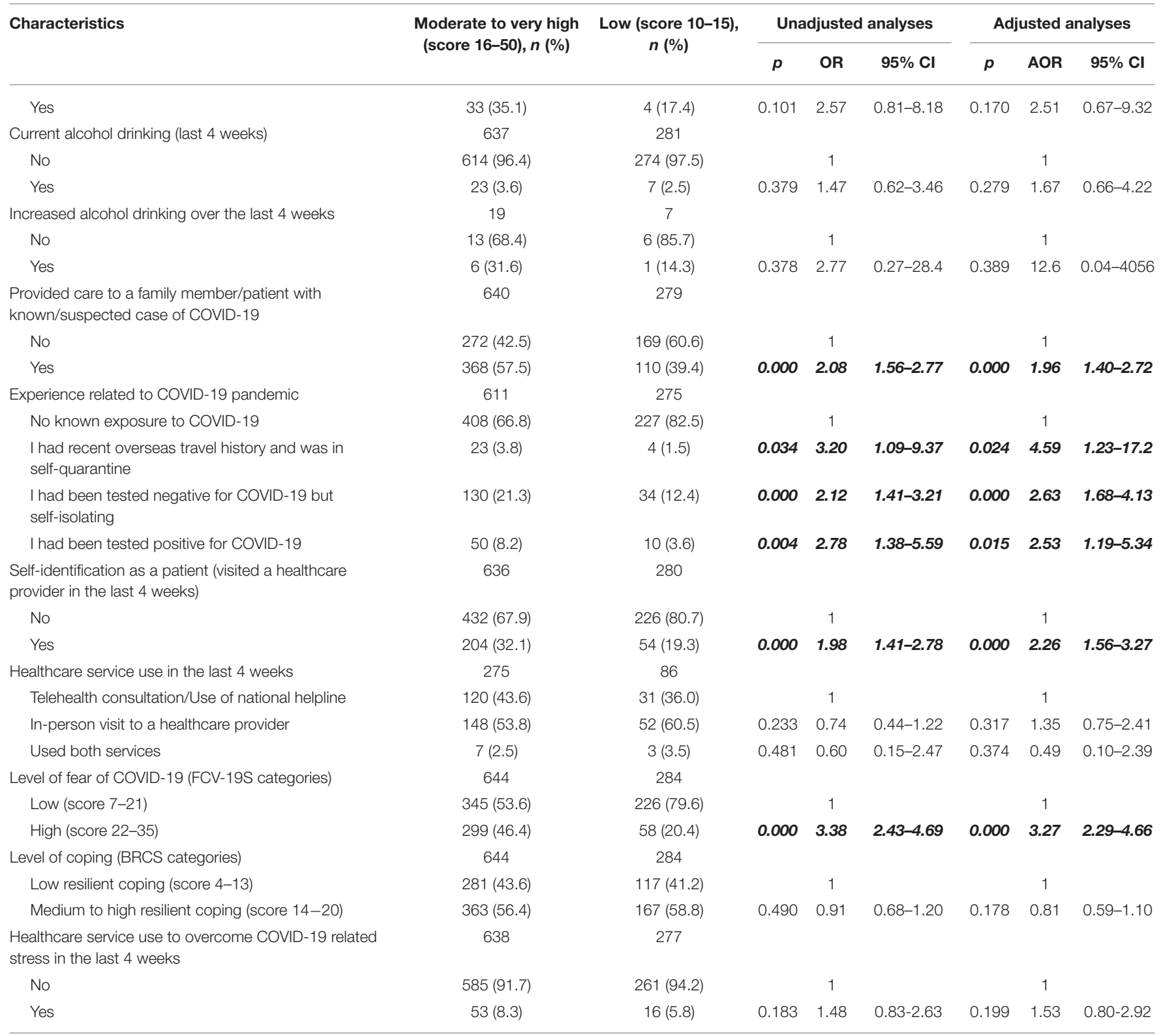

Adjusted for: age, gender, living status, residence location, born in Bangladesh, education and employment.

${ }^{*}$ Cardiac disases/Stroke/Hypertension/Hyperlipidemia/Diabetes/Cancer/Chronic respiratory illness.

Significant results are indicated as bold and italic.

distress and fear. Being born in Bangladesh, having completed graduate level education and above, perceived distress due to change of employment status, COVID-19 impacting financial situation, having multiple co-morbidities and visiting a health care provider in the past 4 weeks was associated with higher levels of psychological distress and fear. Being a female, being a frontline or essential service worker, having pre-existing mental health problems, being an ever smoker, providing care to a known/suspected case of COVID-19, having an overseas travel history, being in quarantine, having negative test results for COVID-19 but being in self-isolation, having positive test results for COVID-19, and having higher levels of fear of COVID-19 was associated with higher psychological distress. In contrast, living in rural areas and having an income source was associated with lower psychological distress. Living with family members and increased psychological distress was associated with a higher level of fear. People who had an income source during the pandemic were more likely to be resilient. However, people with pre-existing mental health conditions were less likely to be resilient.

Around $69 \%$ of respondents experienced moderate to high levels of psychological distress in our study which was similar 
TABLE 6 | Factors associated with high levels of fear of COVID-19 among the study participants (based on FCV-19S score).

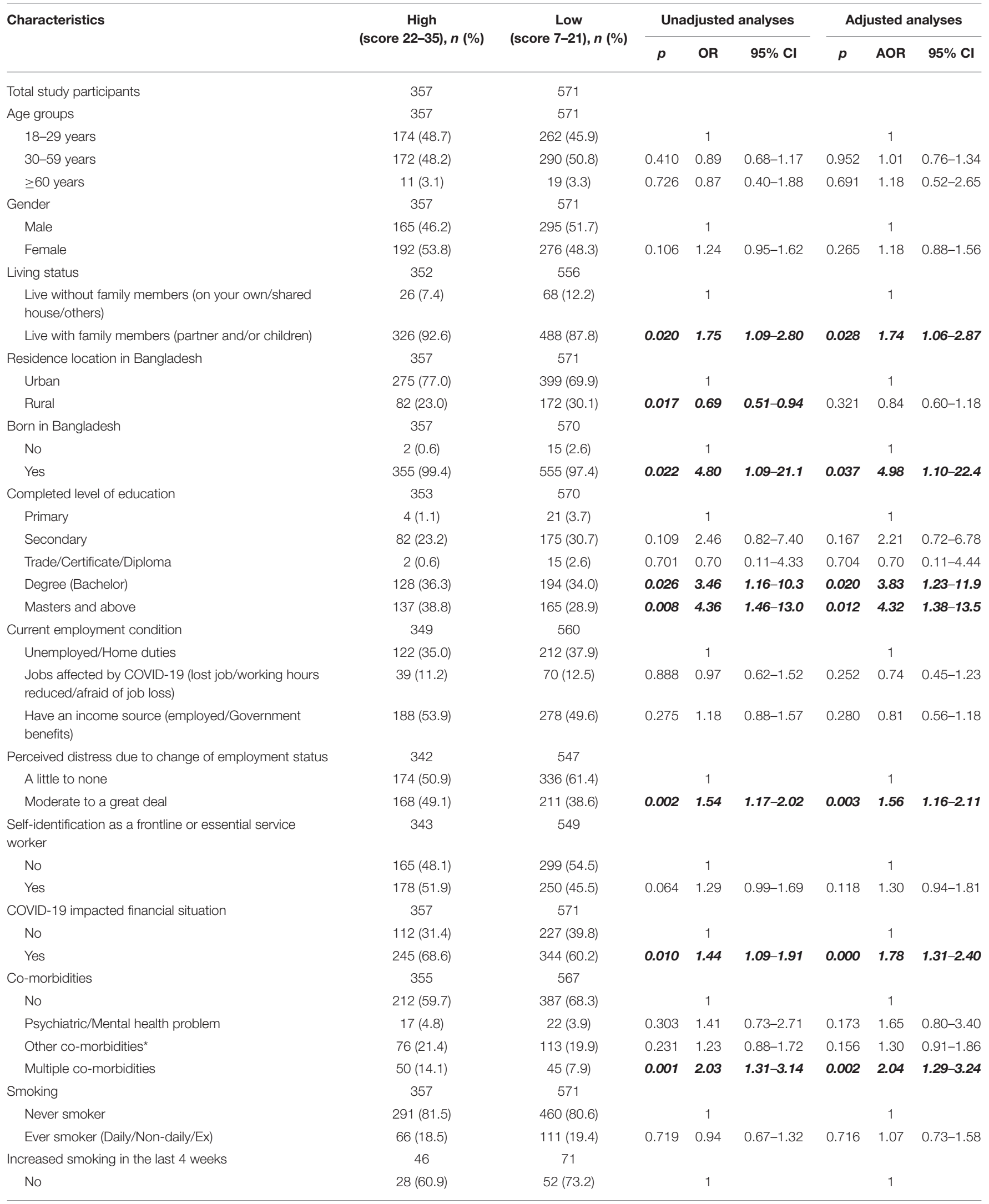


TABLE 6 | Continued

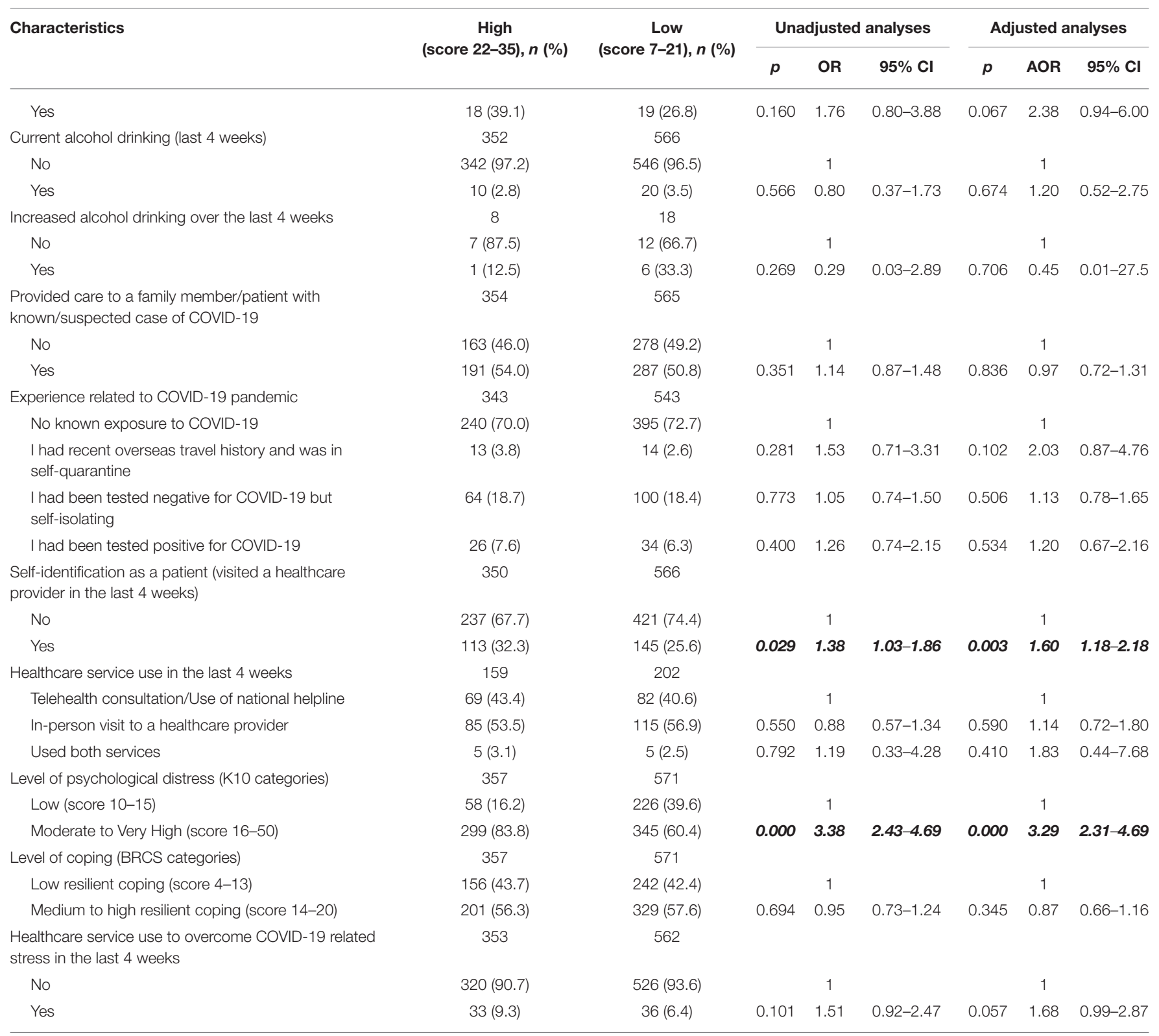

Adjusted for: age, gender, living status, residence location, born in Bangladesh, education and employment.

${ }^{*}$ Cardiac disases/Stroke/Hypertension/Hyperlipidemia/Diabetes/Cancer/Chronic respiratory illness.

Significant results are indicated as bold and italic.

to the findings from a study of psychological distress during the pandemic in Victoria, Australia (63\%) (10) and slightly higher than seen in a nationwide study covering 193 cities in China where $53.8 \%$ of participants reported having moderate to severe psychological distress during the pandemic $(9,12)$. The study finding was also much higher than that found in a national survey (conducted during the non-pandemic period) in Bangladesh where prevalence of mental disorder was between 6.5 and $31.0 \%$ in adults (23) and another large-scale nationwide survey across 64 districts in Bangladesh showed the prevalence of mental illness as around 33\% (24). However, the latter survey was done when COVID 19 pandemic was mostly confined to the imported transmission and no data regarding community spread was reported in Bangladesh. The Australian study also had a good representation of overseas respondents which could explain the similar prevalence of psychological distress in the two studies (10).

Similar to the Australian study, this study also found females and those with mental health problems to be at risk of experiencing higher psychological distress (10). A high level of mental illness was observed in a study among the US people during the 1st month of infection particularly among female, 
TABLE 7 | Factors associated with medium to high resilience coping among the study participants (based on BRCS score).

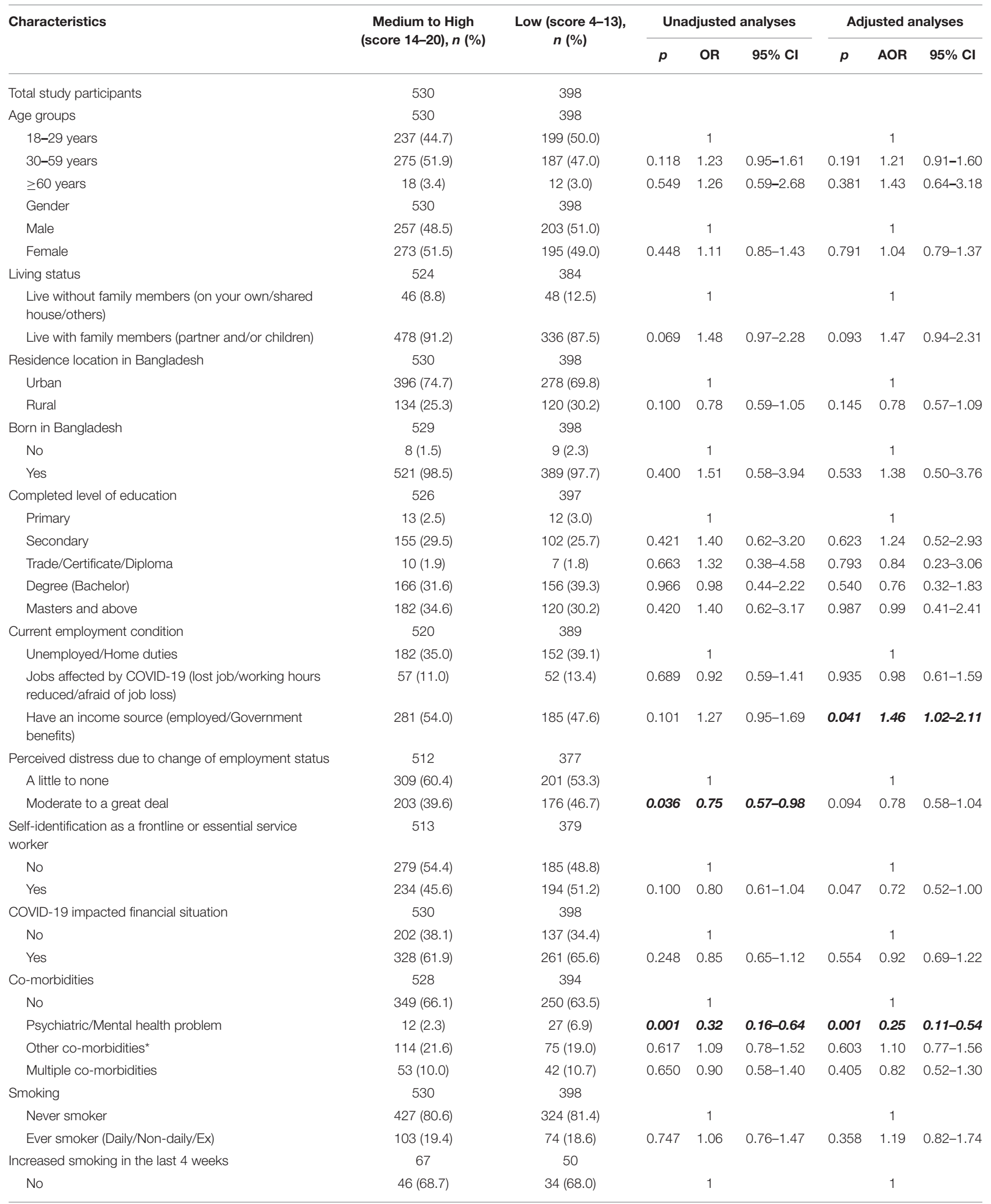


TABLE 7 | Continued

\begin{tabular}{|c|c|c|c|c|c|c|c|c|}
\hline Characteristics & $\begin{array}{c}\text { High } \\
\text { (score 22-35), } n(\%)\end{array}$ & $\begin{array}{c}\text { Low } \\
\text { (score 7-21), } n(\%)\end{array}$ & \multicolumn{3}{|c|}{ Unadjusted analyses } & \multicolumn{3}{|c|}{ Adjusted analyses } \\
\hline Current alcohol drinking (last 4 weeks) & 526 & 392 & & & & & & \\
\hline No & $513(97.5)$ & $375(95.7)$ & & 1 & & & 1 & \\
\hline Yes & $13(2.5)$ & $17(4.3)$ & 0.116 & 0.56 & $0.27-1.17$ & 0.400 & 0.71 & $0.33-1.56$ \\
\hline No & $10(83.3)$ & $9(64.3)$ & & 1 & & & 1 & \\
\hline Yes & $2(16.7)$ & $5(35.7)$ & 0.275 & 0.36 & $0.06-2.34$ & 0.363 & 0.17 & $0.00-7.52$ \\
\hline $\begin{array}{l}\text { Provided care to a family member/patient with } \\
\text { known/suspected case of COVID- } 19\end{array}$ & 528 & 391 & & & & & & \\
\hline No & $252(47.7)$ & $189(48.3)$ & & 1 & & & 1 & \\
\hline Yes & $276(52.3)$ & $202(51.7)$ & 0.855 & 1.03 & $0.79-1.33$ & 0.962 & 1.01 & $0.75-1.35$ \\
\hline $\begin{array}{l}\text { I had been tested negative for COVID-19 but } \\
\text { self-isolating }\end{array}$ & $101(19.9)$ & $63(16.6)$ & 0.111 & 1.33 & $0.94-1.89$ & 0.124 & 1.33 & $0.92-1.93$ \\
\hline I had been tested positive for COVID-19 & $41(8.1)$ & $19(5.0)$ & 0.044 & 1.79 & $1.02-3.15$ & 0.089 & 1.70 & $0.92-3.14$ \\
\hline $\begin{array}{l}\text { Self-identification as a patient (visited a healthcare } \\
\text { provider in the last } 4 \text { weeks) }\end{array}$ & 527 & 389 & & & & & & \\
\hline No & $371(70.4)$ & $287(73.8)$ & & 1 & & & 1 & \\
\hline Yes & $156(29.6)$ & $102(26.2)$ & 0.261 & 1.18 & $0.88-1.59$ & 0.317 & 1.17 & $0.86-1.58$ \\
\hline Healthcare service use in the last 4 weeks & 207 & 154 & & & & & & \\
\hline Telehealth consultation/Use of national helpline & $93(44.9)$ & $58(37.7)$ & & 1 & & & 1 & \\
\hline In-person visit to a healthcare provider & $111(53.6)$ & $89(57.8)$ & 0.253 & 0.78 & $0.51-1.20$ & 0.487 & 0.84 & $0.52-1.36$ \\
\hline $\begin{array}{l}\text { Healthcare service use to overcome COVID-19 related } \\
\text { stress in the last } 4 \text { weeks }\end{array}$ & 524 & 391 & & & & & & \\
\hline No & $484(92.4)$ & $362(92.6)$ & & 1 & & & 1 & \\
\hline Yes & $40(7.6)$ & $29(7.4)$ & 0.902 & 1.03 & $0.63-1.70$ & 0.770 & 1.08 & $0.63-1.85$ \\
\hline
\end{tabular}

Adjusted for: age, gender, living status, residence location, born in Bangladesh, education and employment.

${ }^{*}$ Cardiac disases/Stroke/Hypertension/Hyperlipidemia/Diabetes/Cancer/Chronic respiratory illness.

Significant results are indicated as bold and italic.

Hispanic ethnicity, and those with diagnosed previous mental illness (25). Studies have shown that people with pre-existing mental health disorders including anxiety disorders, existing health anxiety (those who worry excessively about having or contracting illnesses), and depression and post-traumatic stress are at increased risk of higher anxiety during the COVID19 outbreak $(10,26)$. Our study also showed a similarity with significantly higher levels of psychological distress among participants having pre-existing comorbidities such as psychiatric or mental health issues. Individuals who were self-isolating or quarantining also showed a high level of psychological distress, similar to previous findings (27). A sense of stigma from other family members or friends might have contributed to such high levels of distress (28). Similar to previous studies, frontline healthcare workers or essential service holders showed a higher level of distress during the pandemic due to increased work-load, infection of colleagues, death of young professionals, infection of family members, lack of protective measures, and an increase in the frequency of medical violence $(29,30)$.

A major adverse consequence of the COVID-19 pandemic is likely to increase social isolation and loneliness which are strongly associated with psychological distress as found in our 
study. Tracking loneliness and intervening early are important public health priorities. Social isolation and loneliness are distinct and might represent different risk pathways. A higher level of distress was observed in females which was consistent with results from Bangladesh (24), Australia (10), China (31) and the USA (25). This can be postulated due to the effects of long-term stay at home, increased domestic violence (32) and being a focal person as a primary caregiver for the affected person at home (33).

The results of our study illustrated additional aspects of fear and distress. No association was found between fear and having any existing comorbidities or increased healthcare utilization, providing care to family or patients with a known and suspected case of COVID-19. These could be explained as the survey was administered during August 2020 when the number of cases declined as per previous data and the sense of catastrophic nature of the pandemic was not pronounced. The majority of our respondents were essential service workers or frontline workers who already adapted to the situation.

One of the major strengths of this study was the use of validated tools to investigate the factors associated with psychological distress, fear and coping strategies among a large number of the Bangladeshi population during the COVID-19 pandemic. The study, however, was not without limitations. As this study was an online survey, response wise preponderance of the younger people was noted as they were presumably more active on social media and had more online access. The study was conducted in English, so those who were not well-versed in English were not able to take part in the study. Use of snowball sampling technique potentially introduced selection bias and the self-reporting nature of the survey could also lead to reporting bias. However, due to the nationwide restrictions of movement, such sampling method was deemed feasible at that pandemic period. The survey responses in this study were predominantly from Dhaka division, although the survey link was shared all over Bangladesh through various social media platforms and emails. An important limitation from our study is, participants who might have tested positive to COVID-19 or those whose family members have tested positive with COVID-19 infection were likely to have reported more depressive symptoms than those who had not. Therefore, the present findings cannot be generalized to the healthy Bangladeshi population. In addition, we do acknowledge that we might have missed more marginalized or vulnerable group of population in our study (e.g., more isolated, experiencing violence or exploitation, in more intensive or less flexible employment or caring roles, or migrant or other minority status); therefore, our findings were potentially

\section{REFERENCES}

1. Worldometer. COVID-19 Coronavirus Pandemic. (2021). Available online at: https://www.worldometers.info/coronavirus/ (accessed June 01, 2021).

2. Directorate General of Health Services (DGHS) Bangladesh. Coronavirus COVID 19 Dashboard. (2021). Available online at: http://103.247.238.92/ webportal/pages/covid19.php (accessed June 01, 2021). underestimated compared to the actual situations there. Due to the exploratory nature of the study, some of the significant findings could be due to chance (using a significance level of 0.05).

\section{CONCLUSION}

The study shows a high level of psychological distress and fear among Bangladeshi people during the COVID-19 pandemic. People with pre-existing mental illness, females, and frontline workers require special attention as they are most affected by the pandemic leading to increased psychological distress. We have used K-10 and BRCS to assess psychological distress and coping in our study. However, there are other assessment tools to measure those issues, future studies can examine the difference in measurement by using more than one study tool. The risk factors identified in this study will help in designing target-based screening for the at-risk people to reduce the burden of mental health in the society.

\section{DATA AVAILABILITY STATEMENT}

The original contributions generated for this study are included in the article/supplementary material, further inquiries can be directed to the corresponding author/s.

\section{ETHICS STATEMENT}

The studies involving human participants were reviewed and approved by Ethical Review Committee at Enam Medical College (Ref: EMC/ERC/2020/08-2).

\section{AUTHOR CONTRIBUTIONS}

MAR conceived the study and performed the statistical analyses. TB, SR, ASBM, SMA, FS, MS, SMSI, WC, and MAR contributed for planning the study. TB, SR, SMA, FS, and MS drafted the manuscript. TB, SR, AW, SMYA, ZZC, BMMU, and MMR supported data collection activities at local settings. WC and MAR provided critical review of the manuscript. All authors read and approved the final manuscript.

\section{ACKNOWLEDGMENTS}

We would like to acknowledge the support from all the study participants and all the healthcare professionals who assisted us in collecting data for this study. 
after the COVID-19 pandemic: an online survey. Heliyon. (2020) 6:e05057. doi: 10.1016/j.heliyon.2020.e05057

5. Sifat RI. COVID-19 and mental health challenges among the hijra people in Bangladesh. Int J Soc Psychiatry. (2020). doi: 10.1177/0020764020978684. [Epub ahead of print].

6. Shammi M, Bodrud-Doza M, Towfiqul Islam ARM, Rahman MM. COVID-19 pandemic, socioeconomic crisis and human stress in resource-limited settings: a case from Bangladesh. Heliyon. (2020) 6:e04063. doi: 10.1016/j.heliyon.2020.e04063

7. Mahmud I, Azad KAK, Mamun AA, Hoque MM, Mallik MU, Moniruzzaman $\mathrm{M}$, et al. Psychological Assessment of Doctors Working in a Pandemic Condition in Dhaka Medical College Hospital. J Bangladesh Coll Phys Surg. (2020) 38:50-5. doi: 10.3329/jbcps.v38i0.47446

8. Xiong J, Lipsitz O, Nasri F, Lui LMW, Gill H. Phan L, et al. Impact of COVID19 pandemic on mental health in the general population: a systematic review. J Affect Disord. (2020) 277:55-64. doi: 10.1016/j.jad.2020.08.001

9. Wang Y, Kala MP, Jafar TH. Factors associated with psychological distress during the coronavirus disease 2019 (COVID-19) pandemic on the predominantly general population: a systematic review and meta-analysis. PLoS ONE. (2020) 15:e0244630. doi: 10.1371/journal.pone.0244630

10. Rahman MA, Hoque N, Alif SM, Islam SMS, Banik B, Sharif A, et al. Factors associated with psychological distress, fear and coping strategies during the COVID-19 pandemic in Australia. Global Health. (2020) 16:95. doi: 10.1186/s12992-020-00624-w

11. Mazza C, Ricci E, Biondi S, Colasanti M, Ferracutti S, Napoli C. et al. A nationwide survey of psychological distress among italian people during the COVID-19 pandemic: immediate psychological responses and associated factors. Int J Environ Res Public Health. (2021) 17:3165. doi: 10.3390/ijerph17093165

12. Wang C, Pan R, Wan X, Tan Y, Xu L, Ho CS. Immediate psychological responses and associated factors during the initial stage of the 2019 Coronavirus Disease (COVID-19) Epidemic among the General Population in China. Int $J$ Environ Res Public Health. (2020) 17:1729. doi: 10.3390/ijerph17051729

13. Islam SM, Ferdous MZ, Potenza MN. Panic and generalized anxiety during the COVID-19 pandemic among Bangladeshi people: an online pilot survey early in the outbreak. J Affect Disord. (2020) 276:307. doi: 10.1016/j.jad.2020.06.049

14. Worldometer. Bangladesh Population 2020. (2020). Available online at: https://www.worldometers.info/world-population/bangladeshpopulation/ (accessed June 15, 2020).

15. Enticott JC, Lin E, Shawyer F, Russell G, Inder B, Patten S, et al. Prevalence of psychological distress: how do Australia and Canada compare? Aust N Z J Psychiatry. (2018) 52:227-38. doi: 10.1177/0004867417708612

16. Furukawa TA, Kessler RC, Slade T. Andrews G. The performance of the K6 and K10 screening scales for psychological distress in the Australian National Survey of Mental Health and Well-Being. Psychol Med. (2003) 33:357-62. doi: 10.1017/S0033291702006700

17. Ahorsu DK, Lin CY, Imani V, Saffari M, Griffiths MD, Pakpour AH. The fear of COVID-19 scale: development and initial validation. Int J Ment Health Addict. (2020). doi: 10.1007/s11469-020-00270-8. [Epub ahead of print].

18. Sinclair VG, Wallston KA. The development and psychometric evaluation of the Brief Resilient Coping Scale. Assessment. (2004) 11:94-101. doi: 10.1177/1073191103258144

19. Bitan DT, Grossman-Giron A, Bloch Y, Mayer Y, Shiffman N, Shlomo M. Fear of COVID-19 scale: psychometric characteristics, reliability and validity in the Israeli population. Psychiatry Res. (2020) 289:113100. doi: 10.1016/j.psychres.2020.113100

20. Winter T, Riordan BC, Pakpour AH, Griffiths MD, Mason A, Poulgrain JW, et al. Evaluation of the English version of the fear of COVID-19 scale and its relationship with behavior change and political beliefs. Int $J$ Ment Health Addict. (2020). doi: 10.1007/s11469-020-00342-9. [Epub ahead of print].

21. Kocalevent RD, Zenger M, Hinz A, Klapp B, Brahler E. Resilient coping in the general population: standardization of the brief resilient coping scale (BRCS). Health Qual Life Outcomes. (2017) 15:251. doi: 10.1186/s12955-017-0822-6
22. López-Pina J-A, Meseguer-Henarejos A-B, Gascón-Cánovas J-J, NavarroVillalba D-J, Sinclair VG, Wallston KA. Measurement properties of the brief resilient coping scale in patients with systemic lupus erythematosus using rasch analysis. Health Qual Life Outcomes. (2016) 14:128. doi: 10.1186/s12955-016-0534-3

23. Hossain MD, Ahmed HU, Chowdhury WA, Niessen LW, Alam DS. Mental disorders in Bangladesh: a systematic review. BMC Psychiatry. (2014) 14:216. doi: 10.1186/s12888-014-0216-9

24. Mamun MA, Sakib N, Gozal D, Bhuiyan AI, Hossain S, Bodrud-Doza M, et al. The COVID-19 pandemic and serious psychological consequences in Bangladesh: a population-based nationwide study. J Affect Disord. (2021) 279:462-72. doi: 10.1016/j.jad.2020.10.036

25. French MT, Mortensen K, Timming AR. Psychological distress and coronavirus fears during the initial phase of the COVID-19 pandemic in the United States. J Ment Health Policy Econ. (2020) 23:93-100. Available online at: http://www.icmpe.org/test1/journal/issues/v23i3/v23i3abs03.html

26. Smith L, Jacob L, Yakkundi A, McDermott D, Armstrong NC, Barnett $\mathrm{Y}$, et al. Correlates of symptoms of anxiety and depression and mental wellbeing associated with COVID-19: a cross-sectional study of UK-based respondents. Psychiatry Res. (2020) 291:113138. doi: 10.1016/j.psychres.2020. 113138

27. Daly M, Robinson E. Psychological distress and adaptation to the COVID-19 crisis in the United States. J Psychiatr Res. (2020) 136:6039. doi: 10.1016/j.jpsychires.2020.10.035

28. Khanna RC, Honavar SG, Metla AL, Bhattacharya A, Maulik PK. Psychological impact of COVID-19 on ophthalmologists-in-training and practising ophthalmologists in India. Indian J Ophthalmol. (2020) 68:9948. doi: 10.4103/ijo.IJO_1458_20

29. Greenberg N, Docherty M, Gnanapragasam S, Wessely S. Managing mental health challenges faced by healthcare workers during covid-19 pandemic. BMJ. (2020) 368:m1211. doi: 10.1136/bmj.m1211

30. Pappa S, Ntella V, Giannakas T, Giannakoulis VG, Papoutsi E, Katsaounou P. Prevalence of depression, anxiety, and insomnia among healthcare workers during the COVID-19 pandemic: a systematic review and meta-analysis. Brain Behav Immun. (2020) 88:901-7. doi: 10.1016/j.bbi.2020.05.026

31. Qiu J, Shen B, Zhao M, Wang Z, Xie B, Xu Y. A nationwide survey of psychological distress among Chinese people in the COVID-19 epidemic: implications and policy recommendations. Gen Psychiatr. (2020) 33:e100213. doi: 10.1136/gpsych-2020-100213

32. Langer A, Meleis A, Knaul FM, Atun R, Aran M, Arreola-Ornelas H, et al. Women and Health: the key for sustainable development. Lancet. (2015) 386:1165-210. doi: 10.1016/S0140-6736(15)60497-4

33. Sanchez OR, Vale DB, Rodrigues L, Surita FG. Violence against women during the COVID-19 pandemic: an integrative review. Int J Gynaecol Obstet. (2020) 151:180-7. doi: 10.1002/ijgo.13365

Conflict of Interest: The authors declare that the research was conducted in the absence of any commercial or financial relationships that could be construed as a potential conflict of interest.

Publisher's Note: All claims expressed in this article are solely those of the authors and do not necessarily represent those of their affiliated organizations, or those of the publisher, the editors and the reviewers. Any product that may be evaluated in this article, or claim that may be made by its manufacturer, is not guaranteed or endorsed by the publisher.

Copyright $\odot 2021$ Rahman, Rahman, Wazib, Arafat, Chowdhury, Uddin, Rahman, Bahar Moni, Alif, Sultana, Salehin, Islam, Cross and Bahar. This is an open-access article distributed under the terms of the Creative Commons Attribution License (CC $B Y)$. The use, distribution or reproduction in other forums is permitted, provided the original author(s) and the copyright owner(s) are credited and that the original publication in this journal is cited, in accordance with accepted academic practice. No use, distribution or reproduction is permitted which does not comply with these terms. 